\title{
Locus de Controle em uma População do Nordeste Brasileiro'
}

\author{
José Ángel Vera Noriega² \\ Centro de Investigação em Alimentação e Desenvolvimento do Mexico \\ Francisco José Batista de Albuquerque \\ Universidade Federal da Paraíba \\ Jesús Francisco Laborín Alvarez \\ Centro de Investigação em Alimentação e Desenvolvimento do Mexico \\ Liana Mirela Souza Oliveira \\ Universidade Federal da Paraíba \\ Guadalupe Coronado \\ Centro de Investigação em Alimentação e Desenvolvimento do Mexico
}

\begin{abstract}
RESUMO - Estabeleceu-se como objetivo principal desse trabalho realizar comparações inter e intragrupo com relação ao locus de controle em um setor da cultura nordestina (Paraíba) do Brasil e cotejar esses resultados com aqueles auferidos em uma cultura mexicana, mais especificamente do deserto de Sonora. Para tanto, definiu-se como objetivo específico analisar as propriedades psicométricas de um instrumento para avaliar locus de controle. Contou-se com uma amostra de 600 sujeitos divididos por quotas de idade e gênero, formando três grupos de idade (100 mulheres e 100 homens em cada um): 14-22; 23-35 e 36-70 anos. Foram realizadas estatísticas descritivas por cada item, teste T de Student para analisar o poder discriminativo de cada um, análises fatoriais, índices de consistência interna (correlação de Pearson). Utilizou-se a escala de locus de controle de Reyes (1995), validada com dados obtidos na população mexicana, composta de 78 itens, com sete opções de resposta apresentadas na forma tipo Likert pictórico. A análise fatorial indicou a presença de quatro fatores que conformam uma nova escala com 71 itens, que em seu conjunto explicam $36,2 \%$ da variância total, apresentando um alpha de 0,93 . Os resultados permitem concluir pela validade da escala, cuja utilidade está assegurada para as situações em que foi avaliada.
\end{abstract}

Palavras-chave: locus de controle; personalidade; validade por construto; Nordeste brasileiro.

\section{Locus of Control in a Brazilian Northeast Population}

\begin{abstract}
The principal goal of this study was to examine within and between group differences in relation to locus of control in the Northeast of Brazil (Paraiba), and compare these results with those found in Mexico (Sonara desert). For this purpose an analysis of the psychometric properties of an instrument designed to evaluate the locus of control was carried out. The study is based on a sample of 600 subjects, distributed according to age and gender quotas, forming three age groups (each group containing 100 women and 100 men): 14-22; 23-35 and 36-70 years of age. Descriptive statistics for each item, Student $\mathrm{t}$ test to analyse the descriptive power of each item, factor analysis, and internal consistency indexes were calculated. Reyes scale (1995) was used; this instrument was validated for the Mexican population, and consists of 78 items with seven optional answers using a Likert pictorial scale. Factor analysis indicated the existence of four factors that accounted for $36.2 \%$ of the total variance. Afer the deletion of seven items the scale of the remaining 71 items showed a coefficient alpha of .93. From these results one derives the accuracy of the scale, whose utility is guaranteed in situations to which it has been validated.
\end{abstract}

Key words: locus of control; personality; construct validity; Northeast of Brazil.

Latané (1994) menciona um grande número de estudos que demonstram que a cultura torna-se central para muitos processos psicológicos, e que, ao se ignorar essa variável, tem-se como resultado uma ciência distorcida. Para as ciências sociais, um aspecto de grande importância é descrever e explicar como o contexto social ou cultural participa, modula ou influencia as ações das pessoas. Atualmente, com o surgimento e desenvolvimento dos chamados modelos ecológicos, dispõe-se, cada vez mais, de evidências empíricas de que

1 O primeiro autor agradece à CAPES e ao CNPq pelo apoio concedido através de bolsa de professor visitante no curso de mestrado em psicologia social da UFPB.

2 Endereço: Centro de Investigação em Alimentação e Desenvolvimento, A. C. Km. O.6 Carretera a la Victoria, Apartado Postal No. 1735. Hermosillo, Sonora, México C. P. 83000. E-mail: avera@cascabel.ciad.mx a cultura e as instituições sociais afetam e determinam o comportamento humano (Vera, 1997).

Na psicologia, o conceito de cultura tem sido trabalhado ao longo do tempo, porém nem sempre de forma estruturada e bem definida. Com efeito, a existência passada e presente de diferentes teorias e microteorias supõem, de maneira implícita ou explícita, o reconhecimento de fatores ou sistemas externos na explicação e compreensão da personalidade. Estas estruturas sociais e culturais modelam, condicionam ou pré-dispõem o sujeito a atuar de variadas maneiras nos mais diversos cenários. Exemplos de tal influência são os estudos realizados no âmbito da psicologia transcultural por Markus e Kitayama (1991), Fiske (1992) e alguns outros autores, que têm mostrado o papel importante da cultura na cognição, emoção, motivação e conduta social. 
A cultura em que nascem e se desenvolvem os indivíduos pode identificar-se como um grande sistema de informação, construído no percurso histórico pelo qual esses indivíduos, os grupos sociais e a sociedade inteira têm que passar. Tal sistema inclui informações não somente sobre variáveis sociológicas ou estruturais, como as instituições e os grupos, desde a família até o governo de uma nação, mas também variáveis econômicas e psicossociais, bem como sobre condutas, interesses, crenças, filosofias de vida, maneiras sociais compartilhadas e transmitidas na interação social (Díaz, 1991).

Portanto, Latané (1994) define a cultura como sendo um conjunto de crenças, valores e práticas transmitidas socialmente, que caracterizam uma sociedade em um tempo determinado. Com isso, se reconhece que as manifestações ou traços de personalidade possuem dois aspectos: um geral, comum a todas as culturas, e outro com características culturalmente específicas (Vera, 1997). Logo, é importante que a investigação sobre traços de personalidade se realize em diferentes culturas e subculturas, com o objetivo principal de proporcionar uma base para julgar se os resultados experimentais refletem traços únicos de uma cultura em particular ou se podem ser generalizados para outras culturas. Isto se torna possível quando se adota uma lógica de personalidade-cultura e se consideram as premissas socioculturais que predominam na cultura como conceitos úteis para o estudo da identidade nacional (Díaz, 1994).

\section{Locus de Controle}

Rotter (conforme citado por La Rosa, 1986) menciona que o grau em que um indivíduo crê que sua vida se encontra sob seu próprio controle ou sob o controle dos outros, constitui uma dimensão importante da variabilidade individual. A pessoa que acredita ser responsável por seu destino, possui locus de controle interno, enquanto que a pessoa que crê que o bom e o ruim que lhe aconteça está determinado pelo acaso, a sorte ou o poder dos demais, está orientada, fundamentalmente, por um locus de controle externo. $\mathrm{Na}$ literatura existente sobre este tema, verifica-se que Rotter foi o pioneiro na investigação sobre a crença das pessoas de que sua vida está controlada por elas próprias ou pela sociedade e pelos outros (Maddi, 1980).

Controle é a habilidade percebida para alterar significativamente os eventos. Isto significa dizer que não é necessário que as pessoas exerçam realmente controle sobre os eventos relevantes, mas que percebam esse controle. A percepção de controle é o principal determinante da resposta do sujeito (Burger, 1989).

Góngora (1998) menciona o locus de controle como expectativas generalizadas sobre a origem das recompensas e castigos no mundo. Rotter (conforme por La Rosa, 1986) sugere a existência de um controle de reforçamento internoexterno, que diz respeito ao grau com que o indivíduo considera que os reforçamentos são contingentes à sua conduta. Segundo estes autores, pode-se definir Controle Interno (C. I.) e Controle Externo (C. E.) da seguinte maneira: quando se percebe um reforço como não-contingente a alguma ação, mas como questão de sorte, destino, controle dos outros, de poderosos ou como não-previsível pelas forças que o ro- deiam, interpreta-se como crença de controle externo; pelo contrário, se o sujeito percebe o reforço como contingente à sua conduta ou a suas características relativamente permanentes, denomina-se crença de controle interno. Díaz (1982) assinala que os sujeitos com C. E. são aqueles que atribuem o êxito às condições do meio ambiente, enquanto que os sujeitos com C. I. consideram seu êxito como resultado de seu próprio esforço ou habilidades.

Os estudos sobre a externalidade-internalidade têm-se entendido sobre inúmeras áreas de aplicação. Um exemplo disso são os trabalhos sobre a relação entre locus de controle saudável e a execução das condutas relacionadas com a saúde (Benett, Moore, Norman, Murphy \& Tudor, 1997). Parte destas investigações tem refletido uma relação positiva entre as pontuações da dimensão interna e as condutas promotoras de saúde e/ou uma relação negativa entre as pontuações da dimensão sorte e as condutas saudáveis ou positivas.

Também a psicologia do consumidor tem investigado a orientação de controle que os sujeitos têm, mostrando que os consumidores com orientação interna confiam em seu próprio conhecimento para avaliar novos produtos. Os consumidores com orientação externa dependem do conselho de pessoas externas para que lhes guiem na escolha de algum produto (Shiffman \& Kanuk, 1997).

Através de várias investigações, alguns autores têm encontrado que possuir um locus de controle interno (L.C.I.) relaciona-se com alguns aspectos positivos da personalidade do indivíduo. As pessoas com um C.I. se inclinam a solucionar problemas para reduzir o estresse (Anderson, 1977); tratam de melhorar sua vida, são mais persistentes, têm elevado autoconceito e sensações de domínio do ambiente (Valderrama, Betancourt \& Vázquez, 1998); valorizam mais o êxito e rechaçam mais o fracasso, quando os atribuem a si mesmos (Dela Coleta, 1990); e têm maior necessidade de êxito (Andrade \& Reyes, 1996).

Lefcourt (1991) e Rotter (1966) relatam que os indivíduos com C.I. estão mais dependentes da informação relacionada com sua conduta futura; objetivam aumentar suas condições ambientais; atendem mais às habilidades e destrezas de êxito; estão mais preocupados por seus fracassos ou erros; resistem mais às manipulações exteriores e têm aprendizagem mais intencional, alto grau de funcionamento acadêmico e atividades mais positivas de êxito. Ou seja, indivíduos com L.C.I estão mais atentos diante dos aspectos de seu ambiente que lhes proporcionam informação relevante para sua conduta futura e fazem mais esforços para melhorar sua situação. A internalidade está associada com maiores índices de adaptação, satisfação e envolvimento nas atividades do que a externalidade. Além disso, os indivíduos "internos" têm mais motivação para o êxito do que os externos (Sánchez, 1990).

Um aspecto associado com o L.C.E que não se deve excluir, é o processo de incapacidade aprendida, que se dá quando o sujeito identifica sua ausência de controle sobre certas situações cotidianas, atribui o controle a forças externas e apresenta depressão. Supõe-se que a maior falta de controle causa maior atribuição externa e, conseqüentemente, maior depressão.

Do mesmo modo, esta teoria postula que a expectativa de que uma conseqüência seja independente do comportamento diminui a motivação para controlar a consequiência. Isso 
interfere na aprendizagem da conduta que poderá controlar a consequiência. E se a conseqüência é traumática, produz temor, devido a percepção de falta de controle das conseqüências, o que, por sua vez, produz depressão (Seligman, 1977).

Os sujeitos controlados externamente têm mais problemas para criar relações adequadas. Uma vez que não acreditam que a informação interpessoal tenha um papel importante nas relações com os outros, vêem a sorte, a oportunidade, o destino, a fatalidade e o poder de outros como determinantes de seus resultados (Nowicki \& DiGirolamo, 1989).

Robbins (1996) assinala que os indivíduos com inclinação de controle externo estão menos satisfeitos, faltam mais, se envolvem menos com seu trabalho, percebem-se com pouco controle sobre os resultados organizacionais importantes. Ademais, são mais condescendentes e dispostos a seguir instruções. Assim, tudo relacionado com o L. C. E tem efeitos sobre a motivação, cognição e emoção. O primeiro aspecto refere-se ao retardo no início de respostas voluntárias e se revela na passividade, na lentidão intelectual e na inadequação das relações sociais. $\mathrm{O}$ segundo aspecto se caracteriza pela dificuldade de aprender que as respostas produzem resultados, manifestando-se na incapacidade de perceber contingências entre resposta e reforço. $\mathrm{O}$ último efeito é devido à aprendizagem de que as conseqüências são independentes do responder e apresenta-se na diminuição efetiva da agressão e da competência.

Do que foi anteriormente exposto, pode-se constatar, primeiramente, que a evidência empírica sobre externalidade-internalidade foi obtida, predominantemente, nos E.U.A, que podem ser caracterizados, segundo Triandis (1994), como uma cultura tipo individualista, onde a internalidade tem maior sentido e aceitação social. Em segundo lugar, os estudos mostram que a externalidade constitui um núcleo de crenças sobre a lógica dos fenômenos que integra e sintetiza as relações de poder e a organização da sociedade como grupos de referência e de pertença. Para Triandis (1994), é possível que, nas culturas coletivistas, a externalidade sirva para construir um modelo sólido de atitudes, para manter a união e a harmonia entre os grupos sociais. Em uma sociedade individualista, pelo contrário, isso é visto como um aspecto negativo, mesmo quando desconhecemos seu funcionamento em contextos coletivistas.

Considerando a importância de comparações transculturais para contribuir na discussão desse estilo de personalidade, concebido como um parâmetro que se mede através de um continuun proporcional, estabeleceu-se como objetivo principal desse trabalho realizar comparações inter e intra-grupo em um setor da cultura nordestina (Paraíba) do Brasil e cotejar esses resultados com aqueles auferidos em uma cultura mexicana, mais especificamente, do deserto de Sonora.

\section{Método}

\section{Amostra}

Contou-se com 600 participantes selecionados através de uma amostra não-probabilística, por quotas, com idades variando dos 14 aos 70 anos, nascidos no Estado da Paraíba e com tempo de residência neste Estado de, pelo menos, a metade da idade acrescida de cinco anos. Os grupos de idade se dividiram da seguinte maneira: adolescentes (14-22 anos), jovens adultos (23-35 anos), adultos (36-70 anos). Desse modo, obtiveram-se três condições de idade por dois de sexo, com 100 pessoas em cada casela (Tabela 1).

\section{Instrumento}

Foi utilizada a escala de locus de controle de Reyes (1995) validada com dados obtidos na população mexicana (Vera \& Cervantes, 1999). Esta escala é composta por 78 itens, com sete opções de resposta apresentadas na forma tipo Likert pictórico, na qual as respostas se representam por sete quadros equiláteros, ordenados do maior ao menor tamanho, que vai desde completamente de acordo até completamente em desacordo. As instruções se encontram escritas na parte superior da primeira folha do instrumento, em que se menciona que o participante deve marcar com um " $x$ " o quadro que melhor represente sua resposta, entendendo que se ele marca o quadro maior, estará indicando que está completamente de acordo com o item e que ao contrário, se marca o menor, significa que está completamente em desacordo com a afirmação dada no item. Se marcar o quadro que se encontra na metade do contínuo, significa que não está nem completamente de acordo nem completamente em desacordo com o item, o que seria equivalente a "às vezes". O restante dos quadros indica diferentes graus de resposta.

\section{Procedimento}

O instrumento de locus de controle de Reyes (1995) foi aplicado nos participantes de 14 a 22 anos de maneira coletiva, em suas respectivas salas de aulas e para os de 23-35 anos e 36-65 anos, a aplicação foi de maneira tanto coletiva como individual, em seus locais de trabalho, praças, parques e/ou casas.

Os participantes de até 22 anos foram localizados em diferentes níveis educativos. O instrumento foi aplicado de maneira coletiva nas salas de aula. Leram-se as instruções em voz alta e se enfatizou que se tratava de um estudo de caráter confidencial, cujo propósito era conhecer "a forma de ser" do indivíduo paraibano. O tempo de aplicação médio foi de 10 a 15 minutos. Para os participantes maiores de 22 anos, a aplicação se realizou de maneira individual, nos locais de trabalho, escritórios, casas e espaços livres, devido à dificuldade de se encontrar lugares onde estivessem grandes grupos de pessoas com esta idade.

Após a aplicação do instrumento, os dados foram organizados e numerados por grupos de sexo, idade e naturalidade, efetuando-se as atividades de codificação e análise através do programa estatístico SPSS para Windows, versão 7.5 (Nurosis, 1995).

Uma distribuição de frequiências para cada um dos itens e variáveis atributivas foi analisada com o objetivo de aumentar a precisão. Computou-se uma nova variável (locus total) para os 600 casos e obtiveram-se os quartis comparando-se cada um dos itens com o teste $t$ de Student. Empregou-se um Alpha de Cronbach $(\alpha)$, que mediu o nível de associação de cada item com as dimensões do construto. Foi realizada uma análise fatorial pelo método de componentes principais com 
Tabela 1. Distribuição de freqüências das variáveis sócio-demográficas na $\operatorname{amostra}(\mathrm{N}=600)$

\begin{tabular}{lrcc}
\hline \multicolumn{1}{c}{ Variáveis } & N & Porcentagem & F \\
\hline Estado Civil & & & \\
$\quad$ Solteiro & 386 & 65,2 & 1,45 \\
Casado & 170 & 28,7 & \\
$\quad$ Separado & 25 & 4,2 & \\
$\quad$ Viúvo & 11 & 1,9 & \\
\hline Local de Nascimento & & & \\
$\quad$ Região nordeste & 569 & 95,2 & 1,41 \\
Região sul & 12 & 4,2 & \\
Região norte & 3 & 0,6 & \\
ZONA & & & \\
$\quad$ Urbana & 401 & 67,6 & 1,32 \\
$\quad$ Rural & 192 & 32,4 & \\
\hline Escolaridade & & & \\
$\quad$ Fundamental & 84 & 14,4 & 2,28 \\
$\quad$ Médio & 254 & 43,5 & \\
$\quad$ Superior & 246 & 42,1 & \\
\hline
\end{tabular}

rotação varimax, como estratégia para obter as dimensões do constructo. Efetou-se a correlação produto-momento de Pearson $(r)$ entre as dimensões, verificando-se a ortogonalidade e, finalmente, foi feita a análise de variância de uma via (ANOVA-one-way) para observar o efeito das características sócio-demográficas.

\section{Resultados}

As análises descritivas (Tabela 1) indicaram que, da amostra total (600 sujeitos), 386 participantes eram soltei- ros $(65,2 \%), 170$ eram casados $(28,7 \%)$ e 36 eram separados ou sem parceiro $(6,1 \%)$. Em sua maioria, os participantes nasceram na zona nordeste da Paraíba $(95,2 \%)$ e eram provenientes da zona urbana (67,6\%). Quanto ao nível educativo, encontrou-se que a maior parte da amostra tinha completado a segunda fase do ensino fundamental (14,4\%), o ensino médio $(43,5)$ e o ensino superior $(42,1 \%)$.

Em seguida, realizaram-se as análises pertinentes para a obtenção da validade de construto. Calcularam-se os índices de consistência interna da escala através do Alpha de Cronbach, encontrando-se valores superiores a 0,93. Da mesma forma, se levou a cabo uma análise dos Componentes Principais (PC), com rotação varimax, para verificar a validade de construto, observando-se que os itens que compõem a escala apresentam cargas fatoriais superiores a 0,32. A análise indicou a presença de quatro fatores, que conformam uma nova escala com 71 itens, que em seu conjunto explicam $36,2 \%$ da variância total, apresentando um Alpha de 0,93.

$\mathrm{O}$ primeiro fator, denominado C. E., se refere à crença de que são outras pessoas e não o sujeito quem controla a sua própria vida. Este fator mostra uma variância explicada de $54,2 \%$, sendo composto por 22 itens, os quais tem uma carga fatorial maior que 0,40 e um Alpha de 0,91(Tabela 2).

O segundo fator, denominado C. I., que mostra itens referentes ao malogro e ao êxito, devidos ao próprio empenho, esforço, destreza ou habilidade e inteligência, explica 16,8\% da variância e compõe-se de 20 itens, os quais têm peso fatorial acima de 0,35 com um Alpha de 0,88 (Tabela 3).

O terceiro fator, chamado controle interno afiliativo, apresenta itens relacionados com o malogro e o êxito, devidos à simpatia, agrado e sociabilidade da própria pessoa, sendo composto por 16 itens, que têm uma variância explicada de

Tabela 2. Itens que compõem a dimensão controle externo (C.E.) do instrumento de locus de controle

\begin{tabular}{|c|c|c|c|}
\hline Item & Descrição do Item & Carga Fatorial & Média \\
\hline 10 & Casar-me com a pessoa certa depende do que já está escrito. & 0,51 & 3,36 \\
\hline 25 & O que tenho conseguido em minha vida é porque tinha que ser assim. & 0,58 & 3,83 \\
\hline 28 & Os êxitos que tenho se devem a minha boa sorte. & 0,63 & 4,19 \\
\hline 29 & Tenho feito boas amizades por acaso. & 0,52 & 3,98 \\
\hline 33 & Obter um bom trabalho depende da sorte. & 0,69 & 3,99 \\
\hline 35 & Tenho tido boas notas por minha boa sorte. & 0,65 & 3,20 \\
\hline 37 & Fazer um bom casamento é uma questão de sorte. & 0,60 & 4,03 \\
\hline 38 & Faço amizade com as pessoas para ficar bem com os outros. & 0,35 & 3,80 \\
\hline 49 & Tenho conseguido namoradas(os) porque tenho boa sorte. & 0,58 & 3,17 \\
\hline 51 & Tenho que ganhar na loteria para poder ter bastante dinheiro. & 0,48 & 3,12 \\
\hline 52 & Tenho boas oportunidades de trabalho por pura sorte. & 0,67 & 3,06 \\
\hline 56 & Minhas notas dependiam da vontade dos professores. & 0,52 & 2,23 \\
\hline 58 & Se agradar meu chefe posso conseguir melhores postos de trabalho. & 0,40 & 3,74 \\
\hline 06 & Me relaciono com as pessoas por que o destino nos colocou no mesmo caminho. & 0,42 & 4,22 \\
\hline 62 & Tenho tirado boas notas porque os professores gostaram de mim. & 0,53 & 2,28 \\
\hline 64 & Tenho conseguido meus/minhas namorados(as) por acaso. & 0,34 & 4,11 \\
\hline 65 & O que tenho conseguido na minha vida tem sido porque tenho sorte. & 0,74 & 3,40 \\
\hline 66 & O êxito que tenho se deve às coincidências da vida. & 0,69 & 3,53 \\
\hline 67 & Chegar a ter dinheiro suficiente depende do meu destino. & 0,72 & 3,68 \\
\hline 71 & Tenho tido êxito por acaso. & 0,66 & 2,79 \\
\hline 73 & As conquistas que tive na vida se devem ao acaso. & 0,72 & 2,95 \\
\hline 09 & Minha família se mantém unida por obrigação. & 0,49 & 2,60 \\
\hline
\end{tabular}

$\mathrm{N}=600 \quad$ Alpha std $=0,91 \quad$ Variância Explicada $=54,2 \% \quad$ número de itens $=22$ 
Tabela 3. Itens que compõem a dimensão controle interno (C.I.) do instrumento de locus de controle

\begin{tabular}{llcc}
\hline Item & \multicolumn{1}{c}{ Descrição do Item } & Carga Fatorial & Média \\
\hline 11 & Chegar a ter dinheiro suficiente depende de mim. & 0,48 & 5,33 \\
15 & As notas que obtenho se devem ao meu esforço. & 0,46 & 6,35 \\
17 & Tenho tido bons trabalhos por que os tenho procurado. & 0,40 & 6,26 \\
02 & Obter um bom trabalho depende da minha inteligência. & 0,47 & 5,12 \\
21 & O que tenho na vida é fruto da minha luta por isso. & 0,43 & 6,04 \\
23 & Chegar a ter dinheiro suficiente depende da minha inteligência. & 0,67 & 5,16 \\
26 & Obter um bom trabalho depende de minha garra. & 0,56 & 6,30 \\
34 & Me dou bem na vida porque me esforço para isto. & 0,50 & 5,67 \\
39 & Sou responsável pelo êxito que tenha no meu trabalho. & 0,72 & 6,01 \\
43 & As conquistas na minha vida dependem do meu esforço. & 0,66 & 6,25 \\
46 & O êxito que tenho se deve as minhas habilidades. & 0,66 & 5,82 \\
47 & Conseguir melhores postos de trabalho depende de minhas capacidades. & 0,64 & 6,16 \\
50 & O êxito que tenho se deve ao meu esforço. & 0,51 & 6,07 \\
54 & Depende de mim conseguir o que quero. & 0,57 & 5,96 \\
57 & Se as portas se abrem para mim é porque demonstro o que sei. & 0,55 & 5,61 \\
59 & Minha vida ficará melhor se me esforçar para isso. & 0,56 & 3,74 \\
60 & Os sucessos que tenho tido se devem as minhas decisões. & 0,60 & 5,78 \\
68 & O que tenho conseguido em minha vida é porque o tenho procurado. & 0,54 & 5,86 \\
76 & Terei êxito se assim me propuser. & 0,50 & 5,61 \\
07 & O êxito que obtenha dependerá das minhas habilidades. & 6,16 & \\
\hline
\end{tabular}

$\mathrm{N}=600 \quad$ Alpha std $=0,89 \quad$ Variância Explicada $=16,8 \% \quad$ número de items $=20$

Tabela 4. Itens que compõem a dimensão controle interno afiliativo do instrumento de locus de controle

\begin{tabular}{llcc}
\hline Item & \multicolumn{1}{c}{ Descrição do Item } & Carga Fatorial & Média \\
\hline 01 & Meu êxito dependerá da minha forma de tratar os outros. & 0,52 & 5,94 \\
12 & Me relaciono com as pessoas porque me proponho a fazê-lo. & 0,44 & 5,10 \\
13 & Me dou bem na vida porque sou simpático. & 0,66 & 4,54 \\
14 & Tenho tido bons namoros porque me esforço para isto. & 0,37 & 4,09 \\
16 & Estou predestinado a manter meus amigos. & 0,44 & 4,94 \\
18 & Terei êxito se for simpático. & 0,63 & 5,08 \\
24 & Tenho me dado bem com meus parceiros porque tenho me esforçado. & 0,32 & 4,82 \\
03 & Me esforço para buscar uma pessoa adequada para casar-me. & 0,32 & 5,14 \\
30 & Consigo o que quero se agrado as pessoas. & 0,40 & 4,33 \\
31 & Tenho talento para me relacionar com as pessoas. & 0,56 & 5,36 \\
04 & Minha vida melhorará se for simpático para com as pessoas. & 0,45 & 5,79 \\
41 & Por que sou simpático se abrem muitas portas. & 0,36 & 4,62 \\
42 & Estou predestinado a me dar bem com as pessoas do sexo oposto. & 0,38 \\
45 & O número de amigos que tenho se deve ao jeito agradável. & 0,40 & 4,52 \\
70 & O êxito de meu trabalho dependerá do meu grau de simpatia. & 0,46 & 5,51 \\
08 & Mantenho meus amigos porque sou amigável. & & 4,39 \\
\hline
\end{tabular}

$\mathrm{N}=600 \quad$ Alpha std $=0,85 \quad$ Variância explicada $=12,9 \% \quad$ número de items $=16$

$12,9 \%$, com pesos fatoriais maiores que 0,32 e um Alpha de 0,85 (Tabela 4).

Por último, o fator 4, que apresenta itens relacionados com o malogro e o êxito devidos à família e aos amigos, refere-se ao controle interno com relação ao social, tanto para a família como para os amigos. Por isso, este fator se denominou controle de conduta social e se compõe de 13 itens, os quais apresentam uma variância explicada de $15 \%$ e cargas fatoriais superiores a 0,33 com um Alpha de 0,77 (Tabela 5).

Considerando que a categoria social não está referida ao tipo de controle, mas a um tipo de comportamento com afirmações de controle externo e interno, se esperaria uma correlação elevada com os controles externo, interno e afilia- tivo. O mesmo ocorre com o tipo afiliativo, em que somente os controles externo e interno não estão relacionados. Tratase de categorias ortogonais, enquanto que as de afiliação e sociais, relacionadas com os amigos e a família, são interdependentes.

Os resultados obtidos mostram que, para locus de controle externo, são significativas as variáveis idade e escolaridade. Da mesma forma, para a dimensão de controle interno, foram significativas as variáveis: idade, escolaridade e ocupação. Para controle afiliativo e para a conduta social, as variáveis idade e escolaridade se revelam significativas.

Como pode ser observado na Tabela 7 , existem diferenças estatísticas para idade e grau de escolaridade. Para 


\section{J. Á. V. Noriega \& cols.}

Tabela 5. Itens que compõem a dimensão conduta social

\begin{tabular}{llcc}
\hline Item & \multicolumn{1}{c}{ Descrição do Item } & Carga Fatorial & Média \\
\hline 20 & Minha família se mantém unida porque ela assim o quer. & 0,33 & 5,51 \\
22 & Mantenho minha família unida porque assim eu quero. & 0,45 & 4,62 \\
27 & Conservo a meus amigos porque Deus assim o quer. & 0,56 & 5,49 \\
44 & O destino de minha família é estar unida. & 0,51 & 5,30 \\
61 & É minha responsabilidade manter minha família unida. & 0,45 & 4,92 \\
63 & Casar-me com a pessoa certa depende do mandato divino & 0,57 & 4,34 \\
75 & Mantenho unida a minha família. & 0,52 & 5,26 \\
78 & Me entrego a Deus para ter um bom trabalho. & 0,34 & 5,83 \\
19 & Me relaciono com as pessoas por interesse delas. & 0,38 & 2,51 \\
55 & Mantenho meus amigos porque me satisfaz fazê-lo. & 0,51 & 5,39 \\
69 & Mantenho meus amigos por decisão própria. & 0,47 & 5,36 \\
72 & Tenho a quantidade de amigos que eu quero. & 0,53 & 4,10 \\
74 & Me dou bem com as pessoas do sexo oposto por que eu quero que seja assim. & & 3,69 \\
\hline
\end{tabular}

$\mathrm{N}=600 \quad$ Alpha std $=0,77 \quad$ Variância explicada $=15,9 \% \quad$ número de itens $=13$

Tabela 6. Valores obtidos na correlação entre fatores

\begin{tabular}{lcccc}
\hline \multicolumn{1}{c}{ Fator } & Controle externo & Controle interno & Controle externo afiliativo & Controle de conduta social \\
\hline Controle externo & 1,00 & & & \\
Controle interno & 0,18 & 1,00 & 1,00 & \\
Controle externo afiliativo & 0,53 & 0,53 & 0,53 & 1,00 \\
Controle interno social & 0,54 & 0,42 & & \\
\hline
\end{tabular}

$p<0,00$

Tabela 7. Análise de variância para as quatro dimensões de locus de controle e as variáveis sócio- demográficas

\begin{tabular}{|c|c|c|c|c|c|c|c|c|c|}
\hline \multirow[t]{2}{*}{ Variáveis } & \multirow[t]{2}{*}{ GL } & \multicolumn{2}{|c|}{$\begin{array}{l}\text { Controle } \\
\text { externo }\end{array}$} & \multicolumn{2}{|c|}{$\begin{array}{c}\text { Controle } \\
\text { interno }\end{array}$} & \multicolumn{2}{|c|}{$\begin{array}{l}\text { Controle } \\
\text { afiliativo }\end{array}$} & \multicolumn{2}{|c|}{$\begin{array}{c}\text { Controle } \\
\text { de conduta social }\end{array}$} \\
\hline & & $\mathbf{F}$ & $\mathbf{S}$ & $\mathbf{F}$ & $\mathbf{S}$ & $\mathbf{F}$ & $\mathbf{S}$ & $\mathbf{F}$ & $\mathbf{S}$ \\
\hline Idade & 2 & 6,11 & 0,00 & 3,07 & 0,47 & 5,77 & 0,03 & 1,93 & 0,14 \\
\hline Escolaridade & 2 & 14,19 & 0,00 & 6,62 & 0,01 & 18,17 & 0,00 & 10,95 & 0,00 \\
\hline Local de nascimento & 13 & 1,07 & 0,37 & 6,05 & 8,51 & 1,26 & 0,23 & 1,59 & 0,82 \\
\hline Ocupação & 8 & 0,91 & 0,50 & 2,42 & 0,14 & 1,80 & 0,74 & 0,55 & 0,81 \\
\hline Religião & 3 & 0,35 & 0,79 & 0,77 & 9,73 & 0,21 & 0,88 & 0,73 & 0,53 \\
\hline
\end{tabular}

Tabela 8. Resultados da Prova Post Hoc para a variável idade e grau de escolaridade

\begin{tabular}{|c|c|c|c|c|c|}
\hline \multirow[t]{2}{*}{ Idade } & \multirow[t]{2}{*}{$\mathbf{N}$} & $\begin{array}{l}\text { Controle } \\
\text { externo }\end{array}$ & $\begin{array}{c}\text { Controle } \\
\text { interno }\end{array}$ & $\begin{array}{l}\text { Controle } \\
\text { afiliativo }\end{array}$ & $\begin{array}{c}\text { Controle de } \\
\text { conduta social }\end{array}$ \\
\hline & & Média & Média & Média & Média \\
\hline $14-21$ & 200 & 3,25 & 5,68 & 4,91 & 4,68 \\
\hline $22-30$ & 200 & 3,13 & 5,59 & 4,66 & 4,48 \\
\hline $31-60$ & 200 & 3,53 & 5,49 & 4,61 & 4,60 \\
\hline \multirow[t]{2}{*}{ Grau } & \multirow[t]{2}{*}{$\mathbf{N}$} & $\begin{array}{l}\text { Controle } \\
\text { externo }\end{array}$ & $\begin{array}{c}\text { Controle } \\
\text { interno }\end{array}$ & $\begin{array}{l}\text { Controle } \\
\text { afiliativo }\end{array}$ & $\begin{array}{c}\text { Controle de } \\
\text { conduta social }\end{array}$ \\
\hline & & Média & Média & Média & Média \\
\hline Fundamental fase 1 & 83 & 3,65 & 5,73 & 5,01 & 4,79 \\
\hline Fundamental fase 2 & 257 & 3,47 & 5,67 & 4,89 & 4,74 \\
\hline Médio & 244 & 3,01 & 5,45 & 4,46 & 4,36 \\
\hline
\end{tabular}

a variável idade, não se observam diferenças na dimensão de Controle Social. Mas, a variável escolaridade alcançou diferenças significativas para cada uma das dimensões internas-externas.

Posteriormente, ao se realizar a prova Post Hoc (Sheffe), se identificou mais claramente que as citadas variaríeis são significativas para cada dimensão. Para a variável idade, os resultados mostram, na dimensão de controle externo, que o grupo 3 dos adultos (36 a 65 anos) tem uma média mais alta do que a média dos jovens, o que implica que os adultos tendem a oferecer explicações baseadas no destino, sorte ou outros poderes. Para as dimensões de controle interno, 
Tabela 9. Teste t para estado civil, sexo, zona e as dimensões da análise fatorial

\begin{tabular}{|c|c|c|c|c|c|c|c|c|c|c|c|c|c|c|}
\hline \multirow{2}{*}{ Parceiro } & \multirow{2}{*}{$\mathbf{N}$} & \multirow{2}{*}{ GL } & \multicolumn{3}{|c|}{ Controle externo } & \multicolumn{3}{|c|}{ Controle interno } & \multicolumn{3}{|c|}{ Controle afiliativo } & \multicolumn{3}{|c|}{ Controle de conduta social } \\
\hline & & & $\mathbf{X}$ & $\mathbf{T}$ & $\mathbf{P}$ & $\mathbf{X}$ & $\mathbf{T}$ & $\mathbf{P}$ & $\mathbf{x}$ & $\mathbf{T}$ & $\mathbf{P}$ & $\mathbf{X}$ & $\mathbf{T}$ & $\mathbf{P}$ \\
\hline Com & 392 & 590 & 3,22 & 2,31 & 0,06 & 5,65 & 2,53 & 0,00 & 4,61 & 2,26 & 0,04 & 4,57 & 0,69 & 0,64 \\
\hline Sem & 200 & & 3,46 & & & 5,46 & & & 4,60 & & & 4,63 & & \\
\hline \multirow{2}{*}{ Sexo } & \multirow{2}{*}{$\mathbf{N}$} & \multirow{2}{*}{ GL } & \multicolumn{3}{|c|}{ Controle externo } & \multicolumn{3}{|c|}{ Controle interno } & \multicolumn{3}{|c|}{ Controle afiliativo } & \multicolumn{3}{|c|}{ Controle de conduta social } \\
\hline & & & $\mathbf{X}$ & $\mathbf{T}$ & $\mathbf{P}$ & $\mathbf{X}$ & $\mathbf{T}$ & $\mathbf{P}$ & $\mathbf{x}$ & $\mathbf{T}$ & $\mathbf{P}$ & $\mathbf{x}$ & $\mathbf{T}$ & $\mathbf{P}$ \\
\hline Homem & 300 & 598 & 3,23 & 1,48 & 0,38 & 5,54 & 1,47 & 0,88 & 4,68 & 1,07 & 0,93 & 4,52 & 1,64 & 0,01 \\
\hline Mulher & 300 & & 3,37 & & & 5,63 & & & 4,76 & & & 4,65 & & \\
\hline \multirow{2}{*}{ Zona } & \multirow{2}{*}{$\mathbf{N}$} & \multirow{2}{*}{ GL } & \multicolumn{3}{|c|}{ Controle externo } & \multicolumn{3}{|c|}{ Controle interno } & \multicolumn{3}{|c|}{ Controle afiliativo } & \multicolumn{3}{|c|}{ Controle de conduta social } \\
\hline & & & $\mathbf{X}$ & $\mathbf{T}$ & $\mathbf{P}$ & $\mathbf{X}$ & $\mathbf{T}$ & $\mathbf{P}$ & $\mathbf{x}$ & $\mathbf{T}$ & $\mathbf{P}$ & $\mathbf{X}$ & $\mathbf{T}$ & $\mathbf{P}$ \\
\hline Urbana & 399 & 582 & 3,25 & 0,99 & 0,04 & 5,58 & 0,21 & 0,26 & 4,72 & 0,45 & 0,97 & 4,56 & 0,36 & 0,61 \\
\hline Rural & 185 & & 3,36 & & & 5,56 & & & 4,68 & & & 4,60 & & \\
\hline
\end{tabular}

controle afiliativo e controle social, as médias mais altas se apresentaram nos adolescentes e jovens que se encontram entre os 14 e 22 anos, o que sugere que eles percebem sua conduta como responsável pelos malogros (Tabela 8).

Por outro lado, o grau de escolaridade é significativo para as quatro dimensões, que são o controle externo, o controle interno, o controle afiliativo e a conduta social. O grupo de nível de ensino fundamental com as médias mais altas apresenta diferenças estatisticamente significativas (Tabela 8).

Quanto à variável ocupação, pode-se notar que se obteve, na prova Post Hoc para a dimensão de controle interno, uma média comparativamente diferente e alta, com 6,20 para as pessoas que contam com um trabalho de técnico, isto é, que possuem uma carreira técnica ou de especialista.

Para identificar as diferenças de médias intra-grupos, realizou-se o teste $t$ de Student para as variáveis estado civil, sexo e zona, as quais tinham dois níveis, em cada uma das dimensões. Resultaram as seguintes condições: 1 - estado civil: com parceiro (casados) ou sem parceiro (solteiros, viúvos, separados e/ou divorciados); 2 - sexo: feminino ou masculino; 3 - zona: zona urbana ou rural.

Os resultados obtidos mostram que, para a variável estado civil, as médias das dimensões controle interno e controle afiliativo resultam em diferenças estatisticamente significativas. Para a variável sexo, a dimensão de controle social apresenta diferenças significativas, com as médias mais altas sempre para as mulheres. Para a variável zona de origem, observam-se resultados significativos na dimensão de controle externo. As pessoas da zona urbana percebem mais os controles interno e afiliativo, enquanto as pessoas de origem rural percebem mais o controle externo (Tabela 9).

\section{Discussão e Conclusões}

O locus de controle externo aparece para a classe média paraibana com $54 \%$ do total da variância explicada, com um fator homogêneo que não foi possível dividir estatística ou conceitualmente. No México, o estudo de Vera e Cervantes (1999) também apresentou esta dimensão como primeira, porém com 36,5\% de variância explicada; além disso, por sua estrutura de 35 itens, foi possível realizar uma análise fatorial para obter três tipos de controle externo: um mediado pela sorte e o destino, outro mediado pela providência ou destino e o terceiro de tipo afiliativo.

Como sistema de explicação dos êxitos, a afiliação constituiu outro fator independente e consistente. Nesse sentido, depreende-se que para o paraibano (no Brasil), o controle afetivo é uma forma clara e independente de explicar os sucessos e os fracassos, enquanto que, para o habitante de Sonora (México), o controle efetivo forma parte integral do locus externo, reconhecendo-se dentro das explicações místicas e independentes do esforço pessoal.

Somando-se as variâncias explicadas dos controles externo e afetivo, se obtém $67 \%$ da variância total das percepções de controle da conduta. Esta porcentagem alta é explicada pelos recursos externos ou ambientais, relacionados com os outros e com os poderosos (poderes político, eclesiástico, privado e econômico), que são utilizados pela classe média paraibana.O controle interno, com vinte itens e com 16,8 \% de variância explicada, tem uma probabilidade baixa de explicação dos eventos através dos amigos, da família, do trabalho e do parceiro.

Os resultados apóiam o argumento de multidimensionalidade do conceito de locus de controle encontrado por outros autores (La Rosa, 1986; Reyes, 1995), no sentido de que os fatores resultantes são parte de um contínuo do constructo em questão, existindo não somente um pólo ou dois, mas, como se mencionou anteriormente, várias subdimensões que o integram.

Encontraram-se duas dimensões em que a variância explicada aparece em maior proporção. Uma delas é o C. E., que também foi encontrado nos estudos realizados por La Rosa (1986), Reyes (1995), Díaz e Andrade (1984). A outra dimensão é o C.I., descrito por Rotter (1966), La Rosa (1986) e Reyes (1995). Porém, apesar de existirem similitudes, nas dimensões encontradas por outros autores ( Díaz \& Andrade, 1984; La Rosa, 1986; La Rosa, Díaz \& Andrade, 1986; Levenson, 1974; Reyes, 1995; Wallston, Wallston \& Develli, 1978;) também há diferenças, como a quantidade de itens que compõem a escala e a orientação de controle que mostram os sujeitos estudados ( Mercado, Garcia, Fernández \& Gómez, 1993). 
A escala de Rotter (1966) de 23 itens aplicada a 400 universitários, cuja consistência interna é de 0,70 , ao ser comparada com a versão de 59 itens aplicada a 600 sujeitos de 14 a 65 anos mostra uma consistência interna de 0,91.

No estudo de Sonora, as dimensões encontradas foram: controle externo aleatório $(\alpha=0,89)$, teo-causal $(\alpha=0,85)$, afiliativo $(\alpha=0,86)$ e controle interno $(\alpha=0,91)$ (Vera $\&$ Cervantes, 1999). La Rosa (1986) encontrou as seguintes dimensões para uma população no centro do México: 1) fatalismo/sorte $(\alpha=0,89)$, que abarca as crenças num mundo não ordenado onde os reforços, recompensas ou resultados dependem de fatores aleatórios, como a sorte ou o destino; 2) poderosos do macrocosmos ou sub-escalas de submissão política $(\alpha=0,87)$, que se refere a sujeitos com controle e poder, cuja ação repercute na vida do indivíduo, como deputados, políticos, governantes de nações e chefes executivos; 3) afetividade $(\alpha=0,83)$ se refere a situações nas quais o sujeito consegue seus objetivos através de relações afetivas com aqueles que o rodeiam (por exemplo, se trato bem ao meu chefe, posso conseguir melhores postos de trabalho); 4) internalidade instrumental $(\alpha=.82)$, que abarca as situações em que o sujeito controla a sua vida devido a seu esforço, trabalho e capacidades (p. ex.: o que tenho conseguido na vida é porque tenho lutado por isso); 5) poderosos do microcosmos $(\alpha=0,78)$, referem-se a sujeitos com poder, que cercam o indivíduo, controlam os reforços que lhe interessam (p. ex.: minhas notas dependem da vontade de meus professores). A escala empregada por La Rosa mostra uma variância explicada de 40,7\%, com itens que têm um peso fatorial superior a 0,30 .

Os dados coligidos na Paraíba, situada na região Nordeste do Brasil, assemelham-se àqueles encontrados por $\mathrm{La}$ Rosa. As suposições de controle externo são freqüentes em populações latinas que vivem em Estados cujas economias estão marginalizadas pelo governo central, carecendo de um conjunto de políticas sociais para combater a pobreza. Estes Estados federativos têm tido um papel preponderante nos grandes momentos históricos revolucionários da vida contemporânea do século XX. Têm um mínimo de população indígena, mas contam com uma distribuição populacional muito dispersa atingida por uma zona seca e por um controle duro por parte de uns poucos donos de terra, chamados de latifundiários.

Estas condições gerais de vida, as mudanças climáticas e seus efeitos negativos na agricultura, a baixa qualidade da escola pública aliada aos mínimos índices de escolaridade média e a convivência com um poder público autoritário e assistencialista tem, na atualidade, desenvolvido uma personalidade na classe média que vive em zonas de secas, que ainda parece favorecer crenças de uma época de desamparo e fatalismo, na qual o controle externo é quase sempre uma fonte de explicação transcendental para as atividades humanas. O segundo aspecto é que as percepções sobre as expectativas de futuro são planejadas pela possibilidade de um golpe de sorte. As loterias e os jogos de azar, os programas televisivos de auditório, que dispõem de jogos e prêmios e os concursos onde o corpo e sua capacidade funcional definem os critérios de êxito, são percebidos como as grandes possibilidades de mudança para as expectativas, que convivem entre o real e o onírico. Os objetivos de vida e as estratégias para alcançá-las têm a estrutura do menor esforço, com expectativas de êxito que superam as habilidades, competências e possibilidades sociais da classe média.

Revisando-se os dados cuidadosamente, surpreende-se com as médias para cada um dos tipos de controle e com os resultados dos comportamentos. A amostra percebe um controle interno, contudo aleatório. $\mathrm{Na}$ atribuição interna, as médias ficam entre seis e sete, e na atribuição externa fica entre dois e três, para o êxito e malogro. A correlação é negativa, ou seja, quando os participantes dizem que seu êxito se deve ao esforço, estão ao mesmo tempo dizendo que não se devem ao azar. Como as interpretações causais estão justapostas, não se pode crer nas duas coisas de uma só vez, nem com a mesma magnitude, o que permite supor que, para o paraibano, trata-se de um só contínuo conceitual. Da mesma maneira, os controles afiliativo e social parecem fazer parte de um mesmo contínuo, já que uma conduta interpessoal pode explicar-se pela simpatia e pela divindade com um valor quase idêntico.

Aguilar e Andrade (1994) encontraram em uma amostra mexicana, que os homens estabeleciam maiores escores, para a crença externa de controle, do que as mulheres. Isto indicou que os homens, mais que as mulheres, acreditavam mais no controle externo e no poder dos outros, se baseavam mais nas relações afetivas para conseguir o que queriam e delegavam mais a responsabilidade de seus atos a outros sujeitos, como os seus pais, os professores, os chefes e os amigos, entre outros. Este aspecto parece interessante, já que, de acordo com o padrão do varão mexicano, se esperaria que os homens fossem mais internos, pelo fato de serem os pontos fortes das famílias, que "honram as calças". Na amostra da Paraíba, por outro lado, não existem diferenças por sexo, o que faz, pois, supor que tanto homens quanto mulheres apresentam, com maior probabilidade, explicações externas para os seus comportamentos.

Com respeito à idade, observou-se que esta variável se relaciona proporcionalmente com a internalidade e com o controle afiliativo, incrementando as médias dessas dimensões à medida que aumenta. Ou seja, o mundo do paraibano se volta para o afiliativo e para o interno quando adquire, com a idade, as habilidades para saber explorar as vantagens da afiliação a um grupo de referência. Estes dados concordam com os estudos desenvolvidos por Díaz $(1982,1990,1994)$ no contexto mexicano, no sentido de que, com a idade, os sujeitos se tornam internamente controlados.

Com relação ao efeito do nível escolar, foram observadas diferenças significativas no fator social, tendo como padrão de resposta que para menor escolaridade existe a crença de que o social se regula de maneira interna. Este corrobora os resultados reportados por Flores (1995) que assinala uma relação entre escolaridade e locus de controle, no sentido de que conforme aumenta o nível de escolaridade maior a tendência de que os sujeitos possuam um L.C.I, diferente de quem possui um nível baixo de instrução escolar e portanto um L.C.E.

Os sujeitos cuja escolaridade é da primeira fase do ensino fundamental, possuem maior disposição a interpretar sua conduta de acordo com os fatores externos, do que os sujeitos com escolaridade de ensino superior. Apesar das médias do nível superior não serem muito distantes das mé- 
dias dos sujeitos com ensino fundamental da primeira fase, observam-se pequenas diferenças, que fazem supor que os primeiros usam com maior frequiência a sorte, o destino, Deus e as suas relações afetivas como possíveis explicações dos eventos que ocorrem em suas vidas.

O fato de que, nos paraibanos, não existam diferenças por controle interno em sexo, idade e escolaridade e de que a idade não gera diferenças nem no externo nem no interno, pode possivelmente dever-se a que, desde tenra idade, desenvolvam uma orientação de controle interno, ou seja, atribuem às suas características pessoais, como esforço, habilidade e inteligência, os êxitos em sua vida. Isto não significa uma internalidade completa, já que também se faz uso de expressões que denotam externalidade. De modo geral, existe uma orientação de controle interno, refletindo uma orientação ao atribuir, resolver ou afrontar situações difíceis, assim como alcançar metas, intervindo diretamente através do esforço, capacidade, habilidade e inteligência. $O$ que indica que os paraibanos relacionam suas ações com as contingências que estas geram, ou seja, crêem que devido a suas atribuições pessoais conseguem certas metas, como ser aprovado num exame ou ter êxito no trabalho.

O que foi verificado anteriormente, fala de um paraibano com forte capacidade de êxito, dado que percebe os êxitos alcançados em função da sua atenção e esforço. Ao mesmo tempo, oferece ao imaginário coletivo parte desse controle para manter a afiliação ao grupo, incluindo em seu mundo causal aquela simbologia compartilhada através da religião e do sentido comum, às crenças e tradições. È uma causalidade que espera por suas regalias, em uma ordem social onde a afiliação a um grupo pode explicar a ascendência ou a descendência de uma geração.

\section{Referências}

Aguilar, V.R. \& Andrade, P.P. (1994). Orden de nacimiento, autoconcepto y locus de control en adolescentes. La Psicología Social en México, 4, 49-55.

Anderson, C.R. (1977). Locus of control, coping behaviors, and performance in a stress setting: A longitudinal study. Journal of Applied Psychology, 62(4), 446-451.

Andrade, P.P. \& Reyes, L.I. (1996). Locus de control y orientación al logro en hombres y mujeres. Revista de Psicología Social y Personalidad, 12 (1-2), 75-84.

Benett, P., Moore, L., Norman, P., Murphy, S. \& Tudor, C. (1997). Health locus of control and value for health in smokers and nonsmokers. Health Psychology, 16 (2), 179-182.

Burger, J.M. (1989). Negative reactions to increases in perceived personal control. Journal of Personality and Social Psychology, 56 (2), 246-256.

Dela Coleta, J.A. (1990). Principales desarrollos y aplicaciones de la teoría de la atribución de causalidad en el Brasil. Revista de Psicología Social y Personalidad, 6 (1-2), 57-73.

Díaz, G.R. (1982). Psicología del mexicano. 14a edição. México: Trillas.

Díaz, G.R. (1990). ¿Existen rasgos básicos en la personalidad de los mexicanos? Revista Mexicana de Psicología, 7 (1-2), 121-129.

Díaz, G.R. (1994). Psicología del mexicano: Descubrimiento de la etnopsicología. México: Trillas.
Díaz, L.R. \& Andrade, P. P. (1984). Una escala de locus de control para niños mexicanos. Revista Interamericana de Psicología, 18, (1-2), 21-33.

Flores, G.M. (1995). Asertividad y locus de control: efectos de género y nivel de escolaridad en empleados de la ciudad de México. Revista Sonorense de Psicología, 9, (1-2), 55-62.

Fiske, A.P. (1992) The four elementary forms of sociality: framework for a unified theory of social relations. Psychological Review, 99, (4), 689-723.

Góngora, C.E.A. (1998). El enfrentamiento a los problemas y el papel del control: Una visión etnopsicológica en un ecosistema de tradición. Tese de Doutorado não-publicada. México: UNAM.

La Rosa, J. (1986). Escalas de locus de control y autoconcepto: construcción y validación. Tese de Doutorado não-publicada. México: UNAM.

La Rosa, J., Díaz, L.R. \& Andrade, P.P. (1986). Escalas de locus de control: problemas y contribuciones. Revista Mexicana de Psicología, 3 (2), 150-153.

Latané, B. (1994). Una teoría elemental de la cultura. Revista de Psicología Social y Personalidad,10 (2), 109- 122.

Lefcourt, H.M. (1991). Locus de control. Em Robinson, J.P.; Shaver, P.R. \& Wrightsman, L.S. (Orgs.), Measures of personality and social psychological attitudes. (pp. 413-493). California: Academic Press.

Levenson, H. (1974). Activism and powerful others: distinctions within the concept of internal-external control. Journal of Personality Assessment, 34 (3), 377-384.

Maddi, S.R. (1980). Personality theories: A comparative analysis. Illinois: Dorsey Press.

Markus, H.R. \& Kitayama, S. (1991). Culture and the self: implications for cognition, emotion, and motivation. Psychological Review, 98 (2), 224-253.

Mercado, D., García, L., Fernández, G. \& Gómez, J. (1993). Estudio transcultural México-Estados Unidos del cuestionario de estilos atribucionales. Revista Interamericana de Psicología. 28 (1), 73-89.

Nowicki, S. \& DiGirolamo, A. (1989). The association of external locus of control, nonverbal processing difficulties and emotional disturbance. Behavioral Disorders, 15 (1), 28-34.

Nurosis, M.J. (1995). SPSS for windows advanced statistics release 7.5. Chicago: SPSS. Inc.

Reyes, L.I. (1995). Género y control: conceptualización y medición etnopsicológica. Proyecto de investigación no publicado, aprobado y aceptado por CONACYT. México.

Rotter, J.B. (1966). Generalized expectancies for internal versus external control of reinforcement. Psychological Monographs, 80, 1-28.

Sánchez, J.J. (1990). Locus de Control y motivación al logro: diferencias sexuales. Tesis de Licenciatura en Psicología. México: Universidad Intercontinental.

Seligman, M.E.P. (1977). Desamparo: sobre depressão, desenvolvimento e morte. São Paulo: HUCITEC.

Shiffman, L.G. \& Kanuk, L.L. (1997). Comportamiento del consumidor. ( $5^{\mathrm{a}}$ ed.) México: Prentice-Hall Hispanoamericana.

Triandis H.C. (1994). Theoretical and methodological approaches to the study of collectivism and individualism. Em U. Kim, H.C. Triandis, C. Kagitcibasi, S.C. Choi \& G. Ion (Orgs.). Individualism and collectivism: theory, method and applications (pp. 41-51). Thousand Oaks CA: Sage Publications. 
Valderrama, P., Betancourt, M. \& Vázquez, G. (1998). Expectativas generalizadas de control personal en deportistas de alto rendimiento. Psicología Social en México, 2, 59-64.

Vera, N.J.A. (1997). Género y Control en el Noroeste de México: Conceptualización y Medición Etnopsicológica. Proyecto de investigación. Hermosillo, Sonora: Centro de Investigación en Alimentación y Desarrollo, A.C.

Vera, N.J.A. \& Cervantes, M.N.E. (1999) Locus de control en una muestra de residentes del noroeste de México. Psicología y Salud, 10 (2), 237-247.

Recebido em 24.06.2002

Primeira decisão editorial em 21.05.2003

Versão final em 13.10.2003

Aceito em 20.10. 2003

\section{Subscriptions}

Send your order for Subscriptions to the Psicologia: Teoria e Pesquisa to:

Revista Psicologia: Teoria e Pesquisa

Secretaria de Divulgação

Universidade de Brasília - Instituto de Psicologia

70910-900 Brasília - DF

BRAZIL

Rate for individuals US\$ 66

Past single numbers:

US\$ 20

US\$ 37 